\title{
Correction to: Floating hip in polytraumatized patients: complications, mechanism of injury, and surgical strategy
}

\author{
Marco Brioschi ${ }^{1} \cdot$ Filippo Randelli ${ }^{2} \cdot$ Paolo Capitani ${ }^{1} \cdot$ Dario Capitani $^{1}$
}

Published online: 29 November 2021

(c) The Author(s) under exclusive licence to SICOT aisbl 2021

\section{Correction to: International Orthopaedics}

https://doi.org/10.1007/s00264-021-05262-4

The authornames in the original article are all inverted, the correct names should be the below:

Marco Brioschi

Filippo Randelli

Paolo Capitani

Dario Capitani

The original article has been corrected.

Publisher's Note Springer Nature remains neutral with regard to jurisdictional claims in published maps and institutional affiliations.

The original article can be found online at https://doi.org/10.1007/ s00264-021-05262-4.

Marco Brioschi

marcobrioschi@outlook.it

Filippo Randelli

filippo.randelli@fastwebnet.it

Paolo Capitani

paolocapitani.dr@gmail.com

Dario Capitani

dario.capitani@ospedaleniguarda.it

1 Department of Orthopedic Surgery and Traumatology,

Niguarda Hospital, Milan, Italy

2 Hip Department, Azienda Socio Sanitaria Territoriale Centro Specialistico Ortopedico Traumatologico Gaetano Pini-CTO, Milan, Italy 